\title{
Parameter Identification for Solid Oxide Fuel Cell Models: Crucial Comments
}

\author{
Chunyuan Zeng, Bo Yang and Yiming Han* \\ Faculty of Electric Power Engineering, Kunming University of Science and Technology, Kunming, China
}

Keywords: solid oxide fuel cell, hydrogen energy, parameter identification, modeling, optimization methods

\section{INTRODUCTION}

Increasing global energy demand (Zhang et al., 2016; Shen et al., 2019), exhausted fossil fuel resources (Wei Yao et al., 2015; Yang et al., 2015), and deteriorating ecological environment have threatened the healthy development (Liu et al., 2016; Kalyan and Rao, 2021; Noman et al., 2021) of the world. Hence, numerous clean production technologies (Zhang et al., 2015; Bakeer et al., 2021; Iqbal et al., 2021) are conceived as candidates to alleviate energy depletion (Chen et al., 2019; Wang et al., 2020; Dzobo et al., 2021). Among them, hydrogen energy utilization (Yang et al., 2020a) plays a considerable role in alleviating environmental pressure and reconstructing energy structure because of its protruding characteristics of pollution-free and high energy conversion (Erdiwansyah et al., 2021). Besides, hydrogen (Zhang et al., 2021a) is used as an alternative renewable energy supplement, while solid oxide fuel cell (SOFC) techniques arouse extensive attention and research studies due to effective and dependable conversion of chemical energy into electrical energy. It is particularly noteworthy that accurate and reliable SOFC system models are hindered owing to the inherent nonlinearity, strong coupling, and diversification. Therefore, to address the aforementioned obstacles, advanced SOFC modeling approaches (Yang et al., 2020b) with flexible parameter identification technologies should be proposed for better behavior prediction and performance research. At present, the practical application of SOFC modeling and parameter identification is confronted with many challenges. First of all, the current research articles lack the description of overall accurate models about cell stack because the influence of electrical coupling is ignored. Second, after selecting an appropriate model, current parameter identification strategies also have potential defects, while advanced methods are worthy of further consideration and research. This study gives a clarification of the abovementioned problems and puts forward some perspectives on various SOFC modeling and parameter identification technologies.

Specialty section:

This article was submitted to Process and Energy Systems Engineering,

a section of the journal Frontiers in Energy Research

Received: 28 December 2021

Accepted: 13 January 2022

Published: 11 February 2022

Citation:

Zeng C, Yang B and Han Y (2022) Parameter Identification for Solid Oxide Fuel Cell Models: Crucial Comments. Front. Energy Res. 10:844690. doi: 10.3389/fenrg.2022.844690

\section{SOFC MODELING}

Accurate and reliable SOFC system models have a crucial part in maximum power point tracking (MPPT), behavior prediction, performance simulation, and research. For the sake of conducting a specific study on SOFCs from multiple perspectives, numerous modeling methods have been devised, which mainly comprise electrochemical model (Yang et al., 2021a), steady-state model (Jiang et al., 2014), and transient model (Wu et al., 2020). Particularly, the identification parameters of various SOFC models are demonstrated in Table 1 , while the specific meaning of each parameter is detailed in reference (Yang et al., 2020b). Among them, the electrochemical model has the most extensive application in parameter identification, while it is considered to be a vigorous and deep description of electrochemical reaction phenomena of SOFC without involving complex situations such as concentration gradient (Xiong et al., 2018; Yang et al., 2021b). Figure 1 shows the overall 
TABLE 1 | Summarization of identification parameters on various models.
SOFC model

Electrochemical model

Steady-state model 1

Steady-state model 2

Transient model
Identified parameters

$E_{0}, A, R, B, I_{0, a}, I_{0, c}, I_{L}$

$\mathrm{k}_{\mathrm{E}}, \mathrm{k}_{1}, \mathrm{k}_{1}, \mathrm{k}_{2}, \gamma$, and $\delta$

$E_{0}, A, R, B, J_{0}, J_{\max }$

$E_{0}, A, R, B, J_{0}, J_{\max }$ generation process based on the electrochemical mechanism of the SOFC. It is clearly described in the study by Wang et al., (2022) that SOFC output voltage is lower than ideal voltage due to the existence of activation loss, ohmic loss, and concentration loss, which is extremely profitable for understanding and designing SOFC structure. Furthermore, the datasets from cylindrical cells (Pierre, 2010) and tubular cell stacks (Caisheng Wang and Nehrir, 2007) in literature (Xiong et al., 2021) are used for parameter identification of electrochemical models, where simulation research is specific to the type of the SOFC and possesses a certain promotion effect on the refinement of the model. In addition, steady-state models can be subdivided into two types (Yang et al., 2020b) as for easy differentiation to name them steady-state model 1 (Jiang et al., 2014) and steadystate model 2 (El-Hay et al., 2018). Since two steady-state models of the SOFC can be tracked and optimized, several unknown parameters under different operation conditions, that is, model 1 has six parameters and model 2 has seven parameters, upon which more trustworthy and efficient online control and performance study of SOFC systems can be achieved (Jiang et al., 2014; Huang and Turan, 2019). Yang et al., (2020b) describe in detail the voltage and load current $(V-I)$ polarization characteristic of steady-state models 1 and 2 , where it is necessary to cover a more in-depth and comprehensive introduction to difference comparison, advantages/disadvantages, and specific applications. It is worthwhile that neither model can display the response under transient disturbances and lack the capability of dynamic response during load changes. Besides, the transient response mainly depends on the reactant flow and the changes of external environment, such as the change rate of hydrogen, steam, and oxygen; the response time of fuel processors; and load variations, while these factors will cause chemical reaction parameter variation and a certain time delay in practical engineering ( $\mathrm{Xu}$ et al., 2016; El-Hay et al., 2019). Therefore, it is an exceptional and practical discussion trend to investigate both steady-state models and transient models, such as in the study by Wu et al., (2019; Fathy and Rezk, (2022).

Especially, based on the abovementioned three modeling methods (Yahya et al., 2018), the output voltage of the whole cell stack is the number of cells multiplied by the output voltage of a single cell, which is assuming that $V-I$ characteristics of all single SOFCs in the cell stack are same or similar. Nevertheless, due to the existence of electrical coupling, the characteristics (Cao et al., 2011; Chaudhary et al., 2019) of each SOFC make a distinction in practical engineering applications leading to inaccurate parameter identification results or poor model practicability. Under various references, the value range of each parameter to be identified is different in the same model, while there is no literature to emphasize the most scientific and universal value range. Besides, because the range of some unknown parameters is too large, the unreasonable search space results in a long optimization time and low accuracy. As a consequence, it plays an essential role to explore a scientific, precise, and accurate parameter value range in all SOFC models in future research.

\section{METHOD OF PARAMETER IDENTIFICATION}

With the rapid progress of computer technology and artificial intelligence (AI), a great number of meta-heuristic algorithms

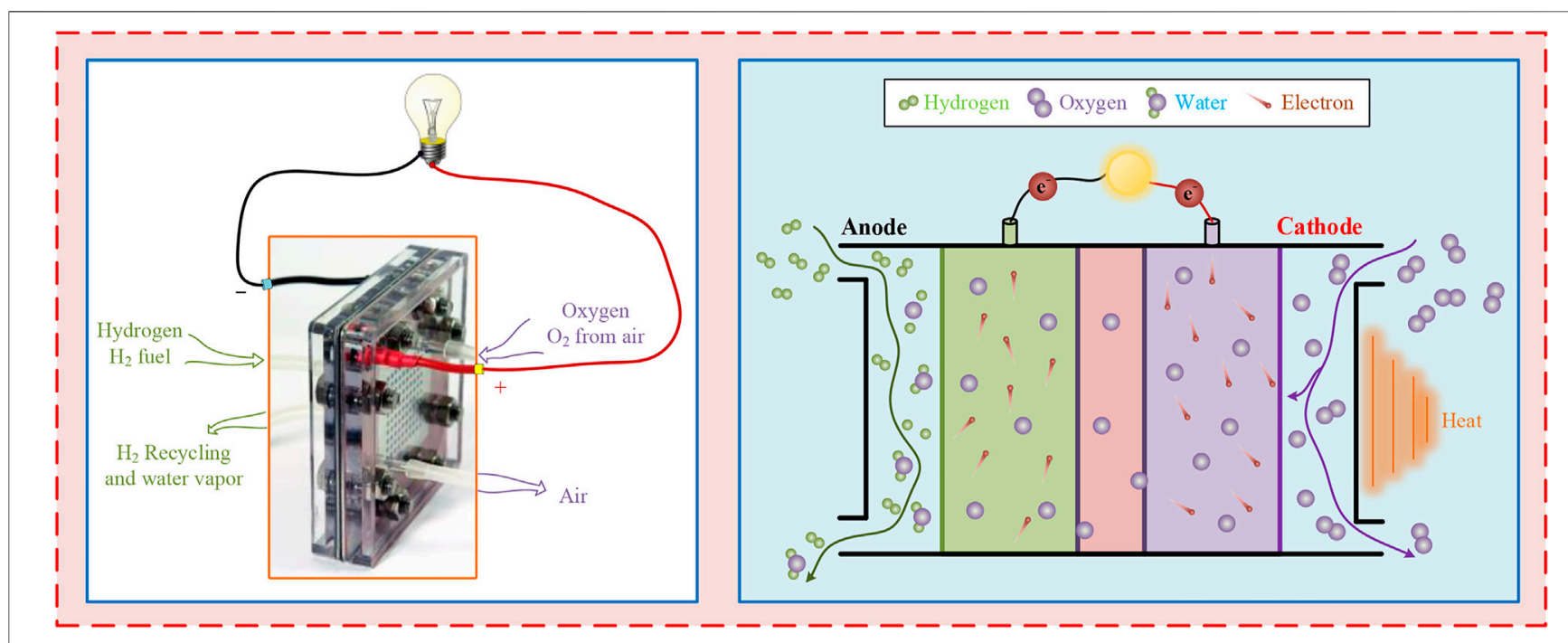

FIGURE 1 | Electrochemical mechanism of the SOFC. 
and artificial neural network (ANN) technologies have been proposed for high nonlinear optimization problems. Meanwhile, these techniques have been supposed to solve a series of parameter identification of the SOFC with high flexibility and low computational pressure due to lack of gradient and complex computational processing. Until now, multitudinous advanced meta-heuristic algorithms have been developed astonishingly to identify unknown parameters in precise SOFC systems. The converged grass fibrous root optimization algorithm (CGROA) (Shi et al., 2020) is a novel optimized technique that is utilized to select unknown parameters in the electrochemical model of the SOFC, where the convergence speed and statistical analysis are applied to present a clearer contrast result. In the study by Wei and Stanford, (2019), an optimized algorithm based on the chaotic binary shark smell optimization (CBSSO) algorithm is recommended, which alleviates the limitations of the optimization process and obtains satisfactory unknown parameter results, upon which superior performance in global search is fully verified. Furthermore, there are other meta-heuristic algorithms with excellent performance, such as interior search optimizer (ISO) (), differential evolution (DE) (Sarmah et al., 2017), co-evolution RNA genetic algorithm (coRNA-GA) (Wang et al., 2019), and simplified variant of competitive swarm optimizer (SCSO) (Xiong et al., 2020).

Although the pure single-algorithm portfolios can acquire satisfactory solutions through multiple iterations, these algorithms also contain certain imperfections (Ghadimi et al., 2018), that is, weak balance ability of local exploitation and global exploration, premature convergence, long calculation time, and insufficient accuracy. In order to amplify the superiorities and partly ameliorate these deficiencies of pure single meta-heuristic algorithms, many scholars have begun to engender more outstanding methods, mainly mixing a variety of metaheuristic algorithms to realize the parameter identification of the SOFC. Bai and Li, (2021) propose a remarkable and accurate method, that is, the combination of cuckoo search (CS) and gray wolf optimization (GWO) algorithm, where using CS changes the static control parameters in GWO to improve precision by reducing the probability of falling into local optimal points. In the study by Xiong et al., (2021), a novel optimization-based hybridization of differential evolution (DE) with the Jaya algorithm is implemented, which makes full use of the exploration character of DE and exploitation character of Jaya to achieve superb performance in a cylindrical cell and a tubular stack. These methods combine two or more meta-heuristic algorithms to improve search accuracy, shorten calculation time, and enhance robustness by complementing the disadvantages of one from the advantages of the other. It is a key direction of meta-heuristic algorithm research and design in the future, especially the number of hybrid meta-heuristic algorithms used to identify unknown parameters of the SOFC is still not enough.

In addition, the integration of meta-heuristic algorithms and ANN models is an alternative research direction extensively discussed at present. Zhang et al., (2021b) propose a novel optimal model of extreme learning machines (ELM) network based on the improved red fox optimization (CRFO) algorithm, upon which parameter identification under nonlinear dynamic behavior of the SOFC stack can be perceived by comparing with the other two methods. Based on the minimizing mean squared error (MSE) between empirical and modeled data, a new hybrid Elman neural network (ENN) method is designed to track unknown parameters of the SOFC efficiently and accurately, which is combined with the quantum pathfinder (QPF) algorithm, called QPF base ENN (QPFENN) (Jia and Taheri, 2021). There is no doubt that the use of various meta-heuristic algorithms to optimize the control parameters of ANN models can take into account the advantages of both, so as to significantly reduce fitting errors and improve accuracy.

However, few scholars pay attention to the shortage of experimental data and noise data, which exists objectively and cannot be ignored in practical engineering. Yang et al., (2021c) provide a perfect research idea, that is, paying attention to the insufficient experimental datasets and random noised datasets in the process of identifying SOFC parameters upon which ELM is applied to predict additional data and update noised data with outstanding stability, great robustness, and high efficiency. At present, several deficiencies need further follow-up research to solve and improve. First of all, more attention should be concentrated on noise data caused by complex operation conditions in order to increase the anti-interference ability of algorithms to identify parameters. In addition, in terms of expanding insufficient data, no standard is elaborated on what is the minimum amount of experimental data to accurately identify unknown parameters.

\section{CONCLUSION}

The precise modeling technology of the SOFC is a crucial step for its performance evaluation, simulation analysis, and subsequent fault diagnosis, while there is still much space to ameliorate in research and development. In particular, various thorny obstacles of present techniques exist in engineering practicability, stability, and efficiency, whose main conclusions are stated as follows:

- Standardized and realistic cell stack models owning perfect practicability for parameter identification have not been devised due to their electrical coupling phenomenon upon which the accuracy and authenticity of models are limited to a great extent. With consideration of various practical factors, the influence of electrical coupling on accurate models can weaken/ avoid.

- Models have the problems of too large parameter boundaries and inconsistency. Thus, it is necessary to formulate a unified standard for the unknown parameter range of each model, while the specific considerations should be combined with different types of cells.

- Multiple hybrid algorithms can make effective use of their advantages simultaneously, which can greatly tackle defects of a single meta-heuristic algorithm and balance the ability 
of local exploitation and global exploration, such as CSGWO, DE-Jaya, and QPF-ENN.

- Noise datasets exist in engineering applications with various complicated conditions, while the current research studies pay little attention. It is worthwhile to focus on noise datasets and find reasonable strategies to remarkably reduce or even eliminate their interferences.

- Another important aspect of this technology is the expansion of insufficient data. The amount of

\section{REFERENCES}

Bai, Q., and Li, H. (2021). The Application of Hybrid Cuckoo Search-Grey Wolf Optimization Algorithm in Optimal Parameters Identification of Solid Oxide Fuel Cell. Int. J. Hydrogen Energ. doi:10.1016/j.ijhydene.2021.11.216

Bakeer, A., Salama, H. S., and Vokony, I. (2021). Integration of PV System with SMES Based on Model Predictive Control for Utility Grid Reliability Improvement. Prot. Control. Mod. Power Syst. 6, 14. doi:10.1186/s41601021-00191-1

Caisheng Wang, C., and Nehrir, M. H. (2007). A Physically Based Dynamic Model for Solid Oxide Fuel Cells. IEEE Trans. Energ. Convers. 22 (4), 887-897. doi:10. 1109/tec.2007.895468

Cao, H., Li, X., Deng, Z., Jiang, J., Yang, J., Li, J., et al. (2011). Dynamic Modeling and Experimental Validation for the Electrical Coupling in a 5-cell Solid Oxide Fuel Cell Stack in the Perspective of thermal Coupling. Int. J. Hydrogen Energ. 36 (7), 4409-4418. doi:10.1016/j.ijhydene.2011.01.032

Chaudhary, T. N., Saleem, U., and Chen, B. (2019). Reacting Flow Coupling with thermal Impacts in a Single Solid Oxide Fuel Cell. Int. J. Hydrogen Energ. 44 (16), 8425-8438. doi:10.1016/j.ijhydene.2019.02.043

Chen, J., Yao, W., Zhang, C.-K., Ren, Y., and Jiang, L. (2019). Design of Robust MPPT Controller for Grid-Connected PMSG-Based Wind Turbine via Perturbation Observation Based Nonlinear Adaptive Control. Renew. Energ. 134, 478-495. doi:10.1016/j.renene.2018.11.048

Dzobo, O., Malila, B., and Sithole, L. (2021). Proposed Framework for Blockchain Technology in a Decentralised Energy Network. Prot. Control. Mod. Power Syst. 6, 30. doi:10.1186/s41601-021-00209-8

El-Hay, E. A., El-Hameed, M. A., and El-Fergany, A. A. (2019). Optimized Parameters of SOFC for Steady State and Transient Simulations Using interior Search Algorithm. Energy 166, 451-461. doi:10.1016/j.energy.2018. 10.038

El-Hay, E. A., El-Hameed, M. A., and El-Fergany, A. A. (2018). Steady-state and Dynamic Models of Solid Oxide Fuel Cells Based on Satin Bowerbird Optimizer. Int. J. Hydrogen Energ. 43, 14751-14761. doi:10.1016/j.ijhydene. 2018.06.032

Erdiwansyah, Mahidin, Husin, H., Nasaruddin, M., Zaki, M., and Muhibbuddin (2021). A Critical Review of the Integration of Renewable Energy Sources with Various Technologies. Prot. Control. Mod. Power Syst. 6, 3. doi:10.1186/s41601021-00181-3

Fathy, A., and Rezk, H. (2022). Political Optimizer Based Approach for Estimating SOFC Optimal Parameters for Static and Dynamic Models. Energy 238, 122031. doi:10.1016/j.energy.2021.122031

Ghadimi, N., Akbarimajd, A., Shayeghi, H., and Abedinia, O. (2018). Two Stage Forecast Engine with Feature Selection Technique and Improved MetaHeuristic Algorithm for Electricity Load Forecasting. Energy 161, 130-142. doi:10.1016/j.energy.2018.07.088

Huang, Y., and Turan, A. (2019). Fuel Sensitivity and Parametric Optimization of SOFC - GT Hybrid System Operational Characteristics. Therm. Sci. Eng. Prog. 14, 100407. doi:10.1016/j.tsep.2019.100407

Iqbal, B., Nasir, A., and Murtaza, A. F. (2021). Stochastic Maximum Power point Tracking of Photovoltaic Energy System under Partial Shading Conditions. Prot. Control. Mod. Power Syst. 6, 30. doi:10.1186/s41601-021-00208-9

Jia, H., and Taheri, B. (2021). Model Identification of Solid Oxide Fuel Cell Using Hybrid Elman Neural Network/quantum Pathfinder Algorithm. Energ. Rep. 7, 3328-3337. doi:10.1016/j.egyr.2021.05.070 experimental data is a considerable research subject, while no research points out the minimum amount of data for parameter identification.

\section{AUTHOR CONTRIBUTIONS}

CZ: writing the original draft and editing. BY: conceptualization. $\mathrm{YH}$ : visualization and contributed to the discussion of the topic.

Jiang, B., Wang, N., and Wang, L. (2014). Parameter Identification for Solid Oxide Fuel Cells Using Cooperative Barebone Particle Swarm Optimization with Hybrid Learning. Int. J. Hydrogen Energ. 39 (1), 532-542. doi:10.1016/j. ijhydene.2013.09.072

Kalyan, C. H. N. S., and Rao, G. S. (2021). Impact of Communication Time Delays on Combined LFC and AVR of a Multi-Area Hybrid System with IPFC-RFBs Coordinated Control Strategy. Prot. Control. Mod. Power Syst. 6, 12. doi:10. 1186/s41601-021-00185-z

Liu, J., Wen, J., Yao, W., and Long, Y. (2016). Solution to Short-term Frequency Response of Wind Farms by Using Energy Storage Systems. IET Renew. Power Generation 10 (5), 669-678. doi:10.1049/iet-rpg.2015.0164

Noman, M., Li, G., Wang, K., and Han, B. (2021). Electrical Control Strategy for an Ocean Energy Conversion System. Prot. Control. Mod. Power Syst. 6, 12. doi:10. 1186/s41601-021-00186-y

Pierre, J. (2010). "Siemens Energy," in 11th Annual SECA Workshop (Pittsburgh, PA: Office of Scientific \& Technical Information Technical Reports).

Sarmah, P., Gogoi, T. K., and Das, R. (2017). Estimation of Operating Parameters of a SOFC Integrated Combined Power Cycle Using Differential Evolution Based Inverse Method. Appl. Therm. Eng. 119, 98-107. doi:10.1016/j.applthermaleng. 2017.03.060

Shen, Y., Yao, W., Wen, J., He, H., and Jiang, L. (2019). Resilient Wide-Area Damping Control Using GrHDP to Tolerate Communication Failures. IEEE Trans. Smart Grid 10 (3), 2547-2557. doi:10.1109/tsg.2018.2803822

Shi, H., Li, J., and Zafetti, N. (2020). New Optimized Technique for Unknown Parameters Selection of SOFC Using Converged Grass Fibrous Root Optimization Algorithm. Energ. Rep. 6, 428-1437. doi:10.1016/j.egyr.2020.05.024

Wang, J., Xu, Y.-P., She, C., Xu, P., and Bagal, H. A. (2022). Optimal Parameter Identification of SOFC Model Using Modified gray Wolf Optimization Algorithm. Energy 240, 122800. doi:10.1016/j.energy.2021.122800

Wang, N., Wang, D., Xing, Y. Z., Shao, L. M., and Afzal, S. (2019). Application of Co-evolution RNA Genetic Algorithm for Obtaining Optimal Parameters of SOFC Model. Renew. Energ. 150, 221-233. doi:10.1016/j.renene.2019.12.105

Wang, Q., Yao, W., Fang, J., Ai, X., Wen, J., Yang, X., et al. (2020). Dynamic Modeling and Small Signal Stability Analysis of Distributed Photovoltaic GridConnected System with Large Scale of Panel Level DC Optimizers. Appl. Energ. 259, 114132. doi:10.1016/j.apenergy.2019.114132

Wei Yao, W., Lin Jiang, L., Jinyu Wen, J. Y., Qinghua Wu, Q. H., and Shijie Cheng, S. J. (2015). Wide-Area Damping Controller for Power System Interarea Oscillations: A Networked Predictive Control Approach. IEEE Trans. Contr. Syst. Technol. 23 (1), 27-36. doi:10.1109/tcst.2014.2311852

Wei, Y., and Stanford, R. J. (2019). Parameter Identification of Solid Oxide Fuel Cell by Chaotic Binary Shark Smell Optimization Method. Energy 188, 115770. doi:10.1016/j.energy.2019.07.100

Wu, Z., Tan, P., Chen, B., Cai, W., Chen, M., Xu, X., et al. (2019). Dynamic Modeling and Operation Strategy of an NG-Fueled SOFC-WGS-TSAPEMFC Hybrid Energy Conversion System for Fuel Cell Vehicle by Using MATLAB/SIMULINK. Energy 175, 567-579. doi:10.1016/j.energy. 2019.03.119

Wu, Z., Zhu, P., Yao, J., Tan, P., Xu, H., Chen, B., et al. (2020). Dynamic Modeling and Operation Strategy of Natural Gas Fueled SOFC-Engine Hybrid Power System with Hydrogen Addition by Metal Hydride for Vehicle Applications. eTransportation 5, 100074. doi:10.1016/j.etran.2020.100074

Xiong, G., Zhang, J., Shi, D., and He, Y. (2018). Parameter Identification of Solid Oxide Fuel Cells with Ranking Teaching-Learning Based Algorithm. Energ. Convers. Manag. 174, 126-137. doi:10.1016/j.enconman.2018.08.039 
Xiong, G., Zhang, J., Shi, D., and Yuan, X. (2020). A Simplified Competitive Swarm Optimizer for Parameter Identification of Solid Oxide Fuel Cells. Energ. Convers. Manag. 203, 112204. doi:10.1016/j.enconman.2019.112204

Xiong, G., Zhang, J., Shi, D., Zhu, L., and Yuan, X. (2021). Optimal Identification of Solid Oxide Fuel Cell Parameters Using a Competitive Hybrid Differential Evolution and Jaya Algorithm. Int. J. Hydrogen Energ. 46 (9), 6720-6733. doi:10.1016/j.ijhydene.2020.11.119

Xu, D., Jiang, B., and Liu, F. (2016). Improved Data Driven Model Free Adaptive Constrained Control for a Solid Oxide Fuel Cell. IET Control. Theor. Appl. 10 (12), 1412-1419. doi:10.1049/iet-cta.2015.0841

Yahya, A., Ferrero, D., Dhahri, H., Leone, P., Slimi, K., and Santarelli, M. (2018). Electrochemical Performance of Solid Oxide Fuel Cell: Experimental Study and Calibrated Model. Energy 142, 932-943. doi:10. 1016/j.energy.2017.10.088

Yang, B., Chen, Y., Guo, Z., Wang, J., Zeng, C., Li, D., et al. (2021). LevenbergMarquardt Backpropagation Algorithm for Parameter Identification of Solid Oxide Fuel Cells. Int. J. Energ. Res 45 (12), 17903-17923. doi:10.1002/er.6929

Yang, B., Guo, Z., Wang, J., Wang, J., Zhu, T., Shu, H., et al. (2021). Solid Oxide Fuel Cell Systems Fault Diagnosis: Critical Summarization, Classification, and Perspectives. J. Energ. Storage 34, 102153. doi:10.1016/j.est.2020.102153

Yang, B., Guo, Z., Yang, Y., Chen, Y., Zhang, R., Su, K., et al. (2021). Extreme Learning Machine Based Meta-Heuristic Algorithms for Parameter Extraction of Solid Oxide Fuel Cells. Appl. Energ. 303, 117630. doi:10.1016/j.apenergy.2021.117630

Yang, B., Jiang, L., Yao, W., and Wu, Q. H. (2015). Perturbation Estimation Based Coordinated Adaptive Passive Control for Multimachine Power Systems. Control. Eng. Pract. 44, 172-192. doi:10.1016/j.conengprac.2015.07.012

Yang, B., Wang, J., Zhang, M., Shu, H., Yu, T., Zhang, X., et al. (2020). A State-OfThe-Art Survey of Solid Oxide Fuel Cell Parameter Identification: Modelling, Methodology, and Perspectives. Energ. Convers. Manag. 213, 112856. doi:10. 1016/j.enconman.2020.112856

Yang, B., Wang, J., Zhang, X., Wang, J., Shu, H., Li, S., et al. (2020). Applications of Battery/supercapacitor Hybrid Energy Storage Systems for Electric Vehicles Using Perturbation Observer Based Robust Control. J. Power Sourc. 448, 227444. doi:10.1016/j.jpowsour.2019.227444
Zhang, K., Zhou, B., Or, S. W., Li, C., Chung, C. Y., and Voropai, N. I. (2021) "Optimal Coordinated Control of Multi-Renewable-To-Hydrogen Production System for Hydrogen Fueling Stations.” in IEEE Transactions on Industry Applications, 30 June 2021, IEEE, 1. doi:10.1109/TIA.2021.3093841

Zhang, M., Xu, Z., Lu, X., Liu, Y., Xiao, Q., and Taheri, B. (2021). An Optimal Model Identification for Solid Oxide Fuel Cell Based on Extreme Learning Machines Optimized by Improved Red Fox Optimization Algorithm. Int. J. Hydrogen Energ. 46 (55), 28270-28281. doi:10.1016/j.ijhydene.2021. 06.046

Zhang, X., Yu, T., Yang, B., and Li, L. (2016). Virtual Generation Tribe Based Robust Collaborative Consensus Algorithm for Dynamic Generation Command Dispatch Optimization of Smart Grid. Energy 101, 34-51. doi:10. 1016/j.energy.2016.02.009

Zhang, X., Yu, T., Yang, B., Zheng, L., and Huang, L. (2015). Approximate Ideal Multi-Objective Solution $\mathrm{Q}(\lambda)$ Learning for Optimal Carbon-Energy Combined-Flow in Multi-Energy Power Systems. Energ. Convers. Manag. 106, 543-556. doi:10.1016/j.enconman.2015.09.049

Conflict of Interest: The authors declare that the research was conducted in the absence of any commercial or financial relationships that could be construed as a potential conflict of interest.

Publisher's Note: All claims expressed in this article are solely those of the authors and do not necessarily represent those of their affiliated organizations, or those of the publisher, the editors, and the reviewers. Any product that may be evaluated in this article, or claim that may be made by its manufacturer, is not guaranteed or endorsed by the publisher.

Copyright (c) 2022 Zeng, Yang and Han. This is an open-access article distributed under the terms of the Creative Commons Attribution License (CC BY). The use, distribution or reproduction in other forums is permitted, provided the original author(s) and the copyright owner(s) are credited and that the original publication in this journal is cited, in accordance with accepted academic practice. No use, distribution or reproduction is permitted which does not comply with these terms. 